\title{
Numerical modelling of modular high-temperature gas-cooled reactors with thorium fuel
}

Mikołaj Oettingen (1), Jerzy Cetnar

\begin{abstract}
The volumetric homogenization method for the simplified modelling of modular high-temperature gas-cooled reactor core with thorium-uranium fuel is presented in the paper. The method significantly reduces the complexity of the 3D numerical model. Hence, the computation time associated with the time-consuming Monte Carlo modelling of neutron transport is considerably reduced. Example results comprise the time evolutions of the effective neutron multiplication factor and fissionable isotopes $\left.{ }^{233} \mathrm{U},{ }^{235} \mathrm{U},{ }^{239} \mathrm{Pu},{ }^{241} \mathrm{Pu}\right)$ for a few configurations of the initial reactor core.
\end{abstract}

Keywords: HTR • Homogenization • Thorium • Monte Carlo

M. Oettingen $\bowtie$

AGH University of Science and Technology

Faculty of Energy and Fuels

Mickiewicza 30 Ave., 30-059 Krakow, Poland

E-mail: moettin@agh.edu.pl

\section{J. Cetnar}

National Centre for Nuclear Research

Andrzeja Sołtana 7 Str., 05-400 Otwock-Świerk, Poland

Received: 17 December 2020

Accepted: 8 January 2021

\section{Introduction}

The design of the nuclear reactor core requires the application of complex methods for reliable reconstruction of the geometry and material composition of the actual reactor core. The greater the complexity of the core geometry is, the longer the computation time of neutron transport will be, especially when using Monte Carlo methods. Additionally, the execution of many input files with varied key parameters is necessary for a comprehensive parametric study. The problem is particularly significant in the modelling of modular high-temperature gas-cooled reactors (MHTRs) with graphite fuel compacts containing spherical TRi-structural ISOtropic (TRISO) particles, called double heterogeneity [1]. In the paper, an alternative method called volumetric homogenization is presented for reducing complexity of the numerical model and the resulting computation time. The method assumes the elimination of double heterogeneity of TRISO particles embedded in the fuel compact. In this method, materials of TRISO particles are admixed to the graphite matrix of the compact and by this way, the complicated geometrical structure of multilayer TRISO particles is eliminated and replaced by one homogenized

0029-5922 @ 2021 The Author(s). Published by the Institute of Nuclear Chemistry and Technology.

This is an open access article under the CC BY-NC-ND 4.0 licence (http://creativecommons.org/licences/by-nc-nd/4.0/). 
material. This, in turn, simplifies the numerical model and speeds up the simulations. The method was applied for the modelling of the MHTR core with thorium-uranium fuel $[2,3]$. This kind of fuel mix is envisaged as an option for the currently designed nuclear reactors, including MHTR [4, 5]. Example results comprise the time evolutions of the effective neutron multiplication factor $K_{\text {eff }}$ and of fissionable isotopes ${ }^{233} \mathrm{U},{ }^{235} \mathrm{U},{ }^{239} \mathrm{Pu},{ }^{241} \mathrm{Pu}$ ) for a few configurations of the initial reactor core. The parametric study includes a variation of geometrical and material parameters of TRISO particles, i.e. kernel radius, packing fraction, enrichment etc. The numerical model of the reactor was developed using the Monte Carlo continuous energy burnup code (MCB) [6, 7]. In the next section, the volumetric homogenization method is comprehensively described. Section "Results" focuses on the design of numerical model and example results. The study is summarized in the last section.

\section{Volumetric homogenization method}

In this section, the volumetric homogenization method is described from the mathematical point of view. Table 1 shows the input parameters necessary to obtain the weight fractions of each isotope in the homogenized material mix and the density of the homogenized material for the Monte Carlo modelling of neutron transport. The presented mathematical set-up was transferred to the numerical script, which automatically calculates the aforementioned parameters using the input data from Table 1.

The calculations begin with the assessment of the volumes of each TRISO material in the fuel compact. The Appendix 1 contains list of symbols used in the applied equations. Initially, the volume of the spherical TRISO fuel kernel $V^{\mathrm{KR}}$ is calculated using Eq. (1), where $r_{\mathrm{KR}}$ is the kernel radius.

$$
V^{\mathrm{KR}}=\frac{4}{3} \pi \cdot r_{\mathrm{KR}}^{3}
$$

Next, the volumes $V_{i}^{\text {TRISO }}$ of each TRISO material wrapping the kernel subsequently are calculated using Eq. (2). $r_{i}$, is the kernel radius $r_{\mathrm{KR}}$ increased by the material layer thickness $t_{i}$, i.e. buffer porous carbon (BPC), inner pyrolytic carbon (IPyC), silicon

Table 1. Input data for the volumetric homogenization method

\begin{tabular}{l}
\hline \multicolumn{1}{c}{ A. Material data } \\
\hline Uranium enrichment \\
Natural abundances of isotopes \\
Atomic weights of isotopes \\
Weight fractions of each dioxide in the dioxide mix \\
Densities of fuel and no-fuel materials \\
\multicolumn{1}{c}{ B. Geometry } \\
TRISO kernel radius \\
TRISO layers thickness \\
TRISO packing fraction \\
Fuel compact radius \\
Fuel compact height
\end{tabular}

carbide ( $\mathrm{SiC})$ and outer pyrolytic carbon $(\mathrm{OPyC})$, subsequently. For the calculating the volume of the BPC that is directly laid on the fuel kernel, it is known that $r_{i-1}$ equals $r_{\mathrm{KR}}$.

$$
V_{i}^{\mathrm{TRISO}}=\frac{4}{3} \pi \cdot\left(r_{i}^{3}-r_{i-1}^{3}\right)
$$

The volume $V^{\mathrm{com}}$ of the cylindrical fuel compact is calculated using Eq. (3), where $r_{\text {Сом }}$ is the compact radius and $h_{\text {Сом }}$ is the compact height.

$$
V^{\mathrm{COM}}=\pi \cdot r_{\mathrm{COM}}^{2} \cdot h_{\text {СОМ }}
$$

In addition, Eq. (1) is used for the calculation of the TRISO particle volume $V^{\mathrm{TRISO}}$, where $r_{\mathrm{KR}}$ is replaced by the radius of the whole TRISO particle $r_{\text {TRISO }}$.

The volumes calculated above may be used in Eq. (4) for calculations of the number of TRISO particles in the fuel compact $N^{\mathrm{TRISO}}$ for a given packing fraction $P$. The packing fraction is defined as the overall volume of all TRISO particles in the compact in relation to the compact volume (Eq. (5)).

$$
\begin{gathered}
N^{\mathrm{TRISO}}=P \cdot \frac{V_{\mathrm{COM}}}{V^{\mathrm{TRISO}}} \\
P=\frac{V^{\mathrm{TRISOinCOM}}}{V^{\mathrm{COM}}}
\end{gathered}
$$

Then, the volume of all TRISO particles in the compact $V^{\text {TRISOincom }}$ and associated volume fractions of each material of TRISO in the compact $V_{i}^{\mathrm{TRISO}, \mathrm{FR}}$ may be calculated by using Eqs. (6) and (7):

$$
\begin{gathered}
V^{\mathrm{TRISOinCOM}}=V^{\mathrm{TRISO}} \cdot N^{\mathrm{TRISO}} \\
V_{i}^{\mathrm{TRISO}, \mathrm{FR}}=\frac{V_{i}^{\mathrm{TRISO}}}{V^{\mathrm{COM}}}
\end{gathered}
$$

Then, with the given densities of each material in the compact $\rho_{i}{ }^{\text {COM }}$, it is possible to calculate the mass of each material in the compact $m_{i}{ }^{\mathrm{COM}}$ and its weight fraction $w_{i}{ }^{\mathrm{COM}, \mathrm{FR}}$ by means of Eqs. (8) and (9). $m^{\mathrm{COM}}$ is the total mass of the compact for a given number of TRISO particles; see Eq. (10).

$$
\begin{gathered}
m_{i}^{\mathrm{COM}}=V_{i}^{\mathrm{TRISO}, \mathrm{FR}} \cdot \rho_{i}^{\mathrm{COM}} \\
w_{i}^{\mathrm{COM}, \mathrm{FR}}=\frac{m_{i}^{\mathrm{COM}}}{m^{\mathrm{COM}}} \\
m^{\mathrm{COM}}=\sum_{i=1}^{n} m_{i}^{\mathrm{COM}}
\end{gathered}
$$

For the input of the Monte Carlo simulations, the density of the homogenized compact $\rho^{\mathrm{HOMO}}$ is also needed. It can be calculated using given densities $\rho_{i}{ }^{\mathrm{COM}}$ and the calculated density of the (U,Th) $\mathrm{O}_{2}$ (Eq. (17)), using Eq. (11).

$$
a_{i}^{\mathrm{U}}=w_{i}^{\mathrm{U}} \cdot \frac{\overline{\mathrm{M}}^{\mathrm{U}}}{\mathrm{M}_{i}^{\mathrm{U}}}
$$

In the next step, the material isotopic composition in the fuel compact is calculated. Initially, the isotopic composition of (U,Th) $\mathrm{O}_{2}$ dioxide for given weight fractions of each dioxide $w_{i}{ }^{(\mathrm{HM}) \mathrm{O}_{2}, \mathrm{FR}}$ in the dioxide mix is considered. The main input param- 
eter is the isotopic composition of uranium with a defined enrichment in ${ }^{235} \mathrm{U}$. The isotopic composition of uranium is usually given as a weight fraction of each uranium isotope $w_{i}^{\mathrm{U}}$. The isotopic compositions of light TRISO materials and graphite matrix are defined by natural abundances, which correspond to atom fractions. Therefore, the isotopic composition of uranium should be recalculated to atom fractions, which was performed using Eq. (12). In the case of thorium, the following recalculation is not necessary since it mainly contains one isotope: ${ }^{232} \mathrm{Th} . a_{i}^{\mathrm{U}}$ is the atom fraction of each uranium isotope, $\mathrm{M}_{i}^{\mathrm{U}}$ is the atomic weight of each uranium isotope and $\overline{\mathrm{M}}^{\mathrm{U}}$ is the average atomic weight for given enrichment, which is calculated using Eq. (13).

$$
\begin{gathered}
a_{i}^{\mathrm{U}}=w_{i}^{\mathrm{U}} \cdot \frac{\overline{\mathrm{M}}^{\mathrm{U}}}{\mathrm{M}_{i}^{\mathrm{U}}} \\
\overline{\mathrm{M}}^{\mathrm{U}}=\left(\sum_{i=1}^{n} \frac{w_{i}^{\mathrm{U}}}{\mathrm{M}_{i}^{\mathrm{U}}}\right)
\end{gathered}
$$

Further, the atom fractions $a_{i}{ }^{(\mathrm{HM}) \mathrm{O}_{2}}$ of each isotope in $\mathrm{UO}_{2}$ and $\mathrm{ThO}_{2}$ dioxides are calculated using Eq. (14), where the index HM corresponds to heavy metal (either $\mathrm{U}$ or Th). $N_{i}{ }^{(\mathrm{HM}) \mathrm{O}_{2}}$ is the average number of atoms of each isotope in the dioxide and $N^{(\mathrm{HM}) \mathrm{O}_{2}}$ is the number of atoms in the dioxide molecule.

$$
a_{i}^{(\mathrm{HM}) \mathrm{O}_{2}}=\frac{N_{i}^{(\mathrm{HM}) \mathrm{O}_{2}}}{N^{(\mathrm{HM}) \mathrm{O}_{2}}}
$$

Then, the atom fraction $a_{i}{ }^{(\mathrm{HM}) \mathrm{O}_{2}, \mathrm{FR}}$ of each dioxide in the dioxide mix is calculated using Eq. (15). The weight fractions of each dioxide in the mix $w_{i}{ }^{(\mathrm{HM}) \mathrm{O}_{2}, \mathrm{FR}}$ are given the input parameters. The atomic weights of each dioxide $\mathrm{M}^{(\mathrm{HM}) \mathrm{O}_{2}}$ are calculated using Eq. (16), while the average atomic weight of the mixed dioxides $\overline{\mathbf{M}}^{(\mathrm{HM}) \mathrm{O}_{2}, \mathrm{MIX}}$ is calculated using Eq. (17), which is a modification of Eq. (13) for molecules.

$$
\begin{gathered}
a_{i}^{(\mathrm{HM}) \mathrm{O}_{2}, \mathrm{FR}}=w_{i}^{(\mathrm{HM}) \mathrm{O}_{2}, \mathrm{FR}} \frac{\overline{\mathrm{M}}^{(\mathrm{HM}) \mathrm{O}_{2}, \mathrm{MIX}}}{\mathrm{M}_{i}^{(\mathrm{HM}) \mathrm{O}_{2}}} \\
\overline{\mathrm{M}}^{(\mathrm{HM}) \mathrm{O}_{2}}=\mathrm{M}^{\mathrm{HM}}+2 \mathrm{M}^{0} \\
\overline{\mathrm{M}}^{(\mathrm{HM}) \mathrm{O}_{2}, \mathrm{MIX}}=\left(\sum_{i=1}^{n} \frac{w_{i}^{(\mathrm{HM}) \mathrm{O}_{2}, \mathrm{FR}}}{\mathrm{M}_{i}^{(\mathrm{HM}) \mathrm{O}_{2}}}\right)
\end{gathered}
$$

Afterwards, the density of mixed dioxides $\rho^{(\mathrm{HM}) \mathrm{O}_{2}}$ for given densities of each dioxide $\rho_{i}{ }^{(\mathrm{HM}) \mathrm{O}_{2}}$ is calculated using Eq. (18) and it is further used for the calculation of the overall density of the homogenized material $\operatorname{mix} \rho^{(\mathrm{HM})}$ (Eq. (11)).

$$
\rho^{(\mathrm{HM}) \mathrm{O}_{2}}=\left(\sum_{i=1}^{n} \frac{w_{i}^{(\mathrm{HM}) \mathrm{O}_{2}, \mathrm{FR}}}{\rho_{i}^{(\mathrm{HM}) \mathrm{O}_{2}}}\right)
$$

Additionally, natural abundances of no-fuel compact and TRISO materials $a_{i}^{\text {ISO }}$ should be recalculated in terms of weight fractions $w_{i}^{\text {ISO }}$, which was performed using Eq. (19).

$$
w_{i}^{\mathrm{ISO}}=a_{i}^{\mathrm{ISO}} \frac{\mathrm{M}_{i}}{\mathrm{M}}
$$

The last stage of calculations considers the preparation of the weight fractions of the homogenized material mix $w_{i}^{\mathrm{HOMO}, \mathrm{ISO}}$ and $w_{i}^{\mathrm{HOMO},(\mathrm{HM}) \mathrm{O}_{2}}$ for neutron transport Monte Carlo simulations. Further, $w_{i}^{\mathrm{HOMO},(\mathrm{HM}) \mathrm{O}_{2}}$ is calculated using Eq. (20), and $w_{i}^{\text {HOMO,ISO }}$ using Eq. (22).

$$
w_{i}^{\mathrm{HOMO},(\mathrm{HM}) \mathrm{O}_{2}}=w_{i}^{\mathrm{COM}, \mathrm{FR}} \cdot w_{i}^{(\mathrm{HM}) \mathrm{O}_{2}, \mathrm{FR}} \cdot w_{i}^{(\mathrm{HM}) \mathrm{O}_{2}}
$$

$w_{i}{ }^{(\mathrm{HM}) \mathrm{O}_{2}}$ corresponds to the weight fractions of each isotope in the dioxide and it is calculated using Eq. (21). The $w_{i}{ }^{\mathrm{COM}, \mathrm{FR}}$ fractions were calculated using Eq. (9).

$$
\begin{aligned}
& w_{i}^{(\mathrm{HM}) \mathrm{O}_{2}}=a_{i}^{(\mathrm{HM}) \mathrm{O}_{2}} \cdot \frac{\overline{\mathrm{M}}^{(\mathrm{HM}) \mathrm{O}_{2}}}{\overline{\mathrm{M}}_{i}^{(\mathrm{HM}) \mathrm{O}_{2}}} \\
& w_{i}^{\mathrm{HOMO}, \mathrm{ISO}}=w_{i}^{\mathrm{COM}, \mathrm{FR}} \cdot w_{i}^{\mathrm{ISO}}
\end{aligned}
$$

The weight fractions of carbon isotopes from different materials are finally summarized to simplify the input for numerical simulations and by this way, the final isotopic composition of the homogenized mix of fuel compact material was defined.

\section{Results}

The example calculations were performed for $180 \mathrm{MW}_{\text {th }}$ MHTR core, as depicted in Fig. 1. The core comprises of 310 hexagonal fuel blocks including 60 blocks with control rods (CR) holes. The numerical Monte Carlo simulations were performed for a two-year irradiation cycle. The MCB code was equipped with JEFF3.2 nuclear data libraries for neutron transport simulations. The reactor core was divided into four radial and 10 axial fuel zones, which gives a total of 40 fuel zones. The geometrical parameters of the core and the TRISO fuel are presented in Tables 2 and 3, respectively.

Table 4 shows four versions of the homogenized thorium-uranium fuel composition. The main criterion is a similar mass of fissionable ${ }^{235} \mathrm{U}$ in the fresh reactor core - about $205 \mathrm{~kg}$. This may be achieved by a variation of the input parameters for the volumetric homogenization method, i.e. kernel radius, weight fraction of each dioxide in the dioxide mix, enrichment and packing fraction.

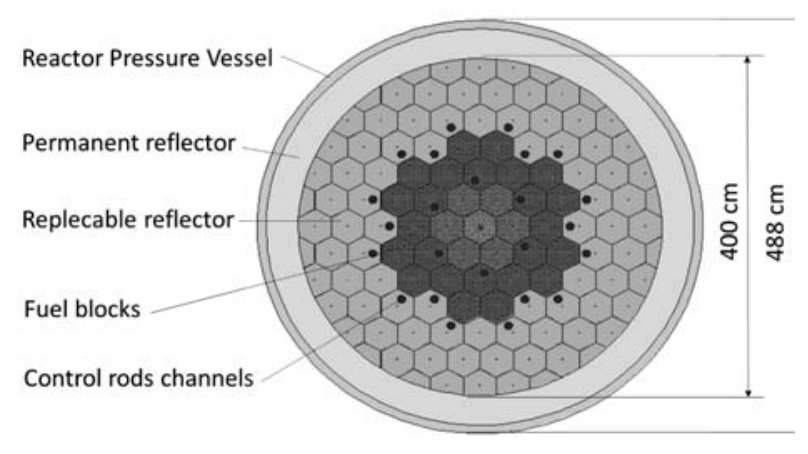

Fig. 1. Radial cross-cut of the reactor core. 
Table 2. Main geometrical parameters of the core

\begin{tabular}{|c|c|}
\hline \multicolumn{2}{|l|}{ Reactor core } \\
\hline Baffle radius $(\mathrm{cm})$ & 200 \\
\hline Active height $(\mathrm{cm})$ & 800 \\
\hline Reflector thickness (top/bottom) (cm) & $120 / 160$ \\
\hline Number of blocks (without CR/with CR) & $250 / 60$ \\
\hline Number of CR (core/reflector) & $12 / 18$ \\
\hline \multicolumn{2}{|l|}{ Fuel block } \\
\hline$\overline{\text { Apothem }(\mathrm{cm})}$ & 18 \\
\hline Height $(\mathrm{cm})$ & 80 \\
\hline Number of cooling channels per block: & \\
\hline - without CR: small/large & $6 / 102$ \\
\hline - with CR: small/large & $7 / 88$ \\
\hline Cooling channel radius (small/large) $(\mathrm{cm})$ & $0.635 / 0.8$ \\
\hline Pitch $(\mathrm{cm})$ & 1.88 \\
\hline Radius of CR channel $(\mathrm{cm})$ & 6.5 \\
\hline Radius of fuel channel (cm) & 0.635 \\
\hline Number of fuel channels & $216 / 182$ \\
\hline \multirow{2}{*}{\multicolumn{2}{|c|}{ Fuel compact }} \\
\hline & \\
\hline $\begin{array}{l}\text { Radius }(\mathrm{cm}) \\
\text { Height }(\mathrm{cm})\end{array}$ & $\begin{array}{l}0.6225 \\
5\end{array}$ \\
\hline
\end{tabular}

Table 3. Geometry of TRISO particles

\begin{tabular}{lcc}
\hline TRISO & Thickness $(\mathrm{mm})$ & Density $\left(\mathrm{g} / \mathrm{cm}^{3}\right)$ \\
\hline Fuel & $600 / 700$ (diameter) & $10.42\left(\mathrm{UO}_{2}\right) / 9.5\left(\mathrm{ThO}_{2}\right)$ \\
\hline BPC & 95 & 1.05 \\
IPyC & 40 & 1.90 \\
SiC & 35 & 3.18 \\
OPyC & 40 & 1.90 \\
\hline
\end{tabular}

Figure 2 shows the evolution of $K_{\text {eff }}$ for the investigated cases. The shapes of the curves are similar in each case. At the beginning, the decrease in $K_{\text {eff }}$ due to the formation of absorbing fission products is observed. Then, $K_{\text {eff }}$ increases to its peak value at about 200 days of irradiation due to the breeding of ${ }^{233} \mathrm{U},{ }^{239} \mathrm{Pu}$ and ${ }^{241} \mathrm{Pu}$ from residual ${ }^{232} \mathrm{Th}$ and ${ }^{238} \mathrm{U}$. Afterwards, $K_{\text {eff }}$ starts to decrease because of the ongoing fuel burnup. The highest values of $K_{\text {eff }}$ were observed in the case $\mathrm{C} 2$ with the lowest mass of Th in the reactor core because of the lower fuel kernel radius. Although the mass of thorium for the subsequent cases $\mathrm{C} 4$ and $\mathrm{C} 1$ is similar, the relative values of $K_{\text {eff }}$ are different; this difference originates from the variations in the initial ${ }^{238} \mathrm{U}$ mass, which is lower in the case C4. The lowest values for $K_{\text {eff }}$ were obtained in the case C3, characterized by the highest volume of ${ }^{232} \mathrm{Th}$ and ${ }^{238} \mathrm{U}$.

The evolution of ${ }^{233} \mathrm{U}$ bred from ${ }^{232} \mathrm{Th}$ is presented in Fig. 3. The mass of the produced ${ }^{233} \mathrm{U}$ depends strictly on the initial mass of ${ }^{232} \mathrm{Th}$. The higher the

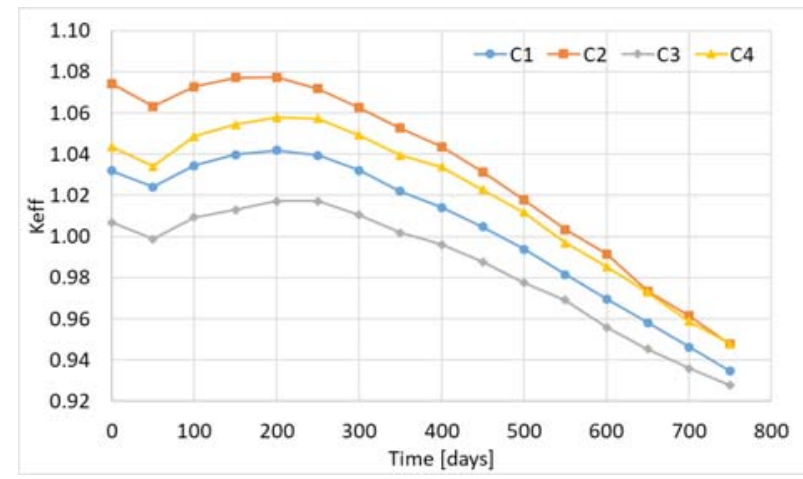

Fig. 2. Evolution of $K_{\text {eff- }}$

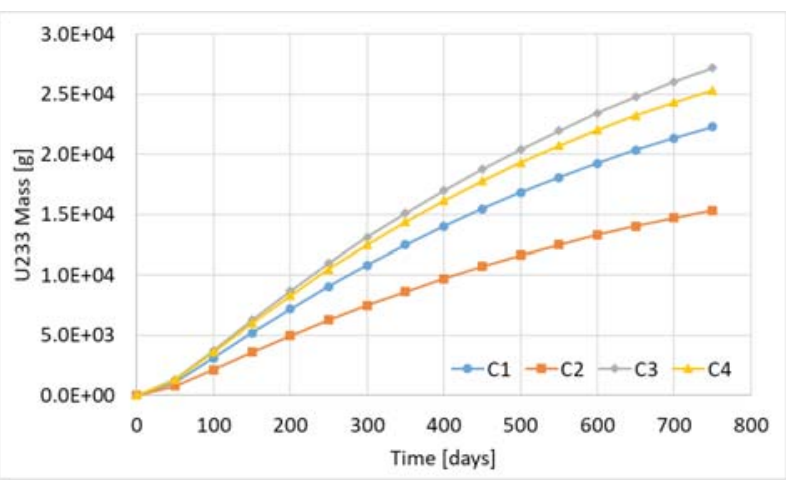

Fig. 3. Evolution of ${ }^{233} \mathrm{U}$.

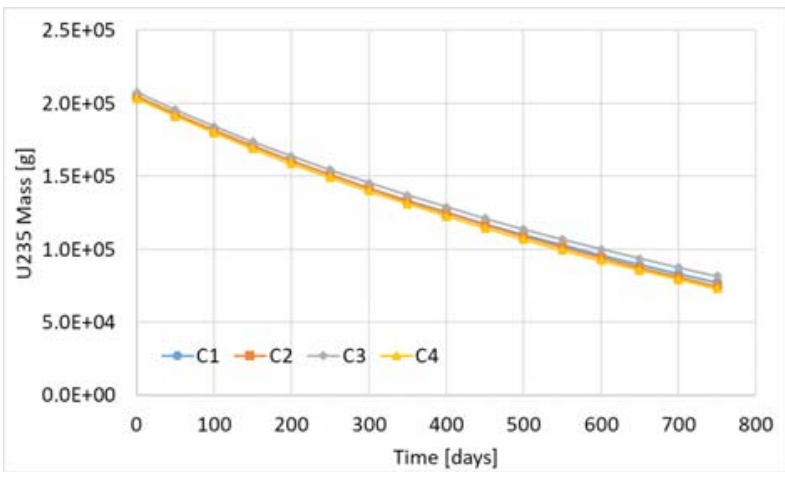

Fig. 4. Evolution of ${ }^{235} \mathrm{U}$.

initial mass of ${ }^{232} \mathrm{Th}$, the faster the production of ${ }^{233} \mathrm{U}$ because of the higher absorption macroscopic cross section of ${ }^{232} \mathrm{Th}$. Therefore, the fastest production of ${ }^{233} \mathrm{U}$ occurs in the case $\mathrm{C} 3$ and the lowest is observed in the case $\mathrm{C} 2$. The decrease of ${ }^{235} \mathrm{U}$ due to the fuel burnup is shown in Fig. 4. The characteristics of all cases $\mathrm{C} 1-\mathrm{C} 4$ are similar due to the presence of almost the same amount of fissionable ${ }^{235} \mathrm{U}$ in the reactor core. The initial mass of ${ }^{235} \mathrm{U}$ decreases by about $60 \%$ during the irradiation period of two years. The production of ${ }^{239} \mathrm{Pu}$ depends on the initial mass of ${ }^{238} \mathrm{U}$, as shown in Fig. 5. The case $\mathrm{C} 4$ with the lowest

Table 4. Fuel parameters for the volumetric homogenization method

\begin{tabular}{lcccccccr}
\hline Case & $\begin{array}{c}r_{\mathrm{KR}} \\
(\mathrm{cm})\end{array}$ & $\begin{array}{c}w^{\mathrm{UO} 2, \mathrm{FR}} \\
(\mathrm{wt} \%)\end{array}$ & $\begin{array}{c}w^{\mathrm{ThO} 2, \mathrm{FR}} \\
(\mathrm{wt} \%)\end{array}$ & $\begin{array}{c}w_{i}{ }^{235} \\
(\%)\end{array}$ & $\begin{array}{c}P \\
(\%)\end{array}$ & $\begin{array}{c}\text { Mass }{ }^{235} \mathrm{U} \\
(\mathrm{kg})\end{array}$ & $\begin{array}{c}\text { Mass }{ }^{238} \mathrm{U} \\
(\mathrm{kg})\end{array}$ & $\begin{array}{c}\text { Mass }{ }^{232} \mathrm{Th} \\
(\mathrm{kg})\end{array}$ \\
\hline 1 & 0.35 & 50 & 50 & 20 & 15 & 204.76 & 816.46 & 1018.70 \\
2 & 0.30 & 40 & 60 & 20 & 15 & 205.05 & 820.22 & 681.43 \\
3 & 0.35 & 55 & 45 & 20 & 17 & 207.68 & 832.01 & 1267.00 \\
4 & 0.35 & 60 & 40 & 25 & 15 & 203.35 & 610.04 & 1216.20 \\
\hline
\end{tabular}




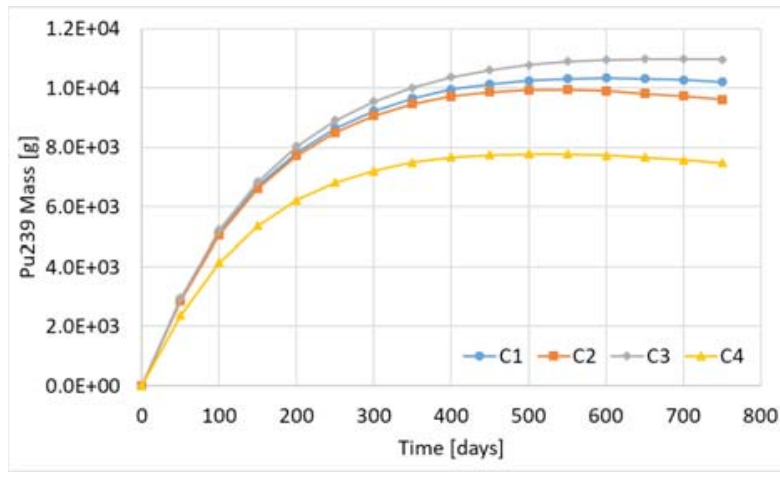

Fig. 5. Evolution of ${ }^{239} \mathrm{Pu}$.

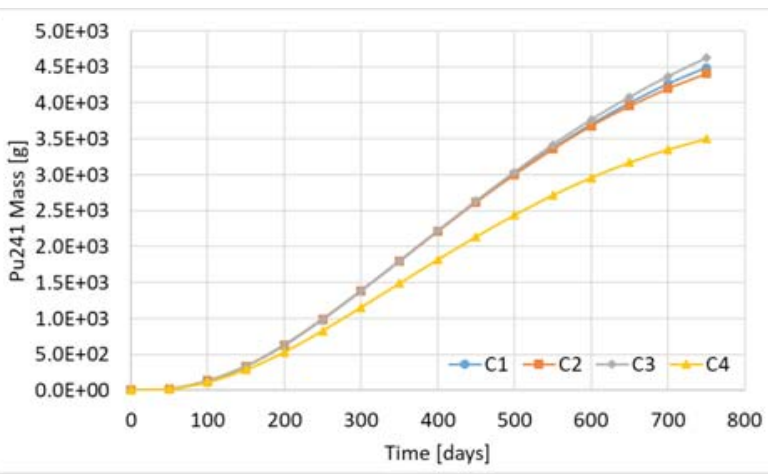

Fig. 6. Evolution of ${ }^{241} \mathrm{Pu}$.

initial mass of ${ }^{238} \mathrm{U}$ shows the lowest production of ${ }^{239} \mathrm{Pu}$ and ${ }^{241} \mathrm{Pu}$ (Fig. 6). The production of ${ }^{239} \mathrm{Pu}$ and ${ }^{241} \mathrm{Pu}$ is similar in other cases, where the initial mass of ${ }^{238} \mathrm{U}$ is similar. However, during the ongoing fuel burnup, a difference in the shapes of the plutonium curves appears, which is related to the depletion of fissionable ${ }^{235} \mathrm{U}$ and its replacement by ${ }^{233} \mathrm{U}$ and plutonium isotopes as secondary fuel. This process is unambiguously observed in the case $\mathrm{C} 2$, where the mass of ${ }^{239} \mathrm{Pu}$ starts to decrease after reaching its peak at about 500 days of irradiation. In this case, the production of ${ }^{233} \mathrm{U}$ is the lowest; therefore, ${ }^{235} \mathrm{U}$ is replaced by fissionable plutonium isotopes, mainly ${ }^{239} \mathrm{Pu}$.

\section{Conclusions}

The volumetric homogenization method for the modelling of the MHTR core was presented in this study. This method was applied for the numerical Monte Carlo modelling of neutron transport in the MHTR core with thorium-uranium fuel. The example results of the modelling were presented. The results prove the reliability of the method for the initial screening of the reactor core performance. The universal character of this method makes it suitable for the numerical modelling of any type of material fuel composition and geometry. Thus, the method can be used not only for the MHTR modelling but also for the modelling of any fissionable system with a complicated fuel geometry, especially using linear chain method [8]. Further study on this method will focus on benchmarking with a full 3D MHTR core model with double heterogeneity of the TRISO fuel. This will allow the verification of the simplified models developed and their use as a replacement of detailed models. In the benchmarking process, the condition under which a defined replacement may happen will be also determined. The benchmarking will define the areas of the reactor core physics that can be reliably modelled using the volumetric homogenization method, e.g. radiotoxicity of the spent nuclear fuel [9], which may facilitate the whole MHTR design methodology.

Acknowledgments. The research was partially supported by PL Grid Infrastructure, available at the Academic Computer Centre CYFRONET AGH. Additionally, partial financial support under the scientific subvention 16.16.210.476 by the Polish Ministry of Science and Higher Education is kindly acknowledged.

\section{ORCID}

J. Cetnar (D) http://orcid.org/0000-0002-0163-3331

M. Oettingen (D) http://orcid.org/0000-0001-7499-7585

\section{References}

1. Talamo, A., Ji, W., Cetnar, J., \& Gudowski, W. (2006). Comparison of MCB and MONTEBURNS Monte Carlo burnup codes on a one-pass deep burn. Ann. Nucl. Energy, 33(14/15), 1176-1188. doi.org/10.1016/j. anucene.2006.08.006.

2. International Atomic Energy Agency. (2012). Role of thorium to supplement fuel cycles of future nuclear energy systems. Vienna: IAEA. (Nuclear Energy Series NF-T-2.4).

3. International Atomic Energy Agency. (2005). Thorium fuel cycle - Potential benefits and challenges. Vienna: IAEA. (IAEA-TECDOC-1450).

4. Shamanin, I. V., Grachev, V. M., Chertkov, Yu. B., Bedenko, S. V., Mendoza, O., \& Knyshev, V. V. (2018). Neutronic properties of high-temperature gas-cooled reactors with thorium fuel. Ann. Nucl. Energy, 113, 286-293. DOI: 10.1016/j.anucene.2017.11.045.

5. Oettingen, M., \& Stanisz, P. (2018). Monte Carlo modelling of $\mathrm{Th}-\mathrm{Pb}$ fuel assembly with californium neutron source. Nukleonika, 63(3), 87-91. DOI: 10.2478/ nuka-2018-0011.

6. Cetnar, J. (2006). Solution of Bateman equations for nuclear transmutations. Ann. Nucl. Energy, 33, 640-645. DOI: 10.1016/j.anucene.2006.02.004.

7. Oettingen, M., Cetnar, J., \& Mirowski, T. (2015). The MCB code for numerical modelling of fourth generation nuclear reactors. Computer Science, 16, 329-350. DOI: $10.7494 /$ csci.2015.16.4.329.

8. Cetnar, J., Stanisz, P., \& Oettingen, M. (2021). Linear chain method for numerical modelling of burnup systems. Energies, 14, 1520. https://doi.org/10.3390/ en14061520.

9. Oettingen, M. (2021). Assessment of the radiotoxicity of spent nuclear fuel from a fleet of PWR reactors (2021). Energies, 14, 3094. https://doi.org/10.3390/ en14113094. 


\section{Appendix I - List of symbols}

Volumes $\left(\mathrm{cm}^{3}\right)$

\begin{tabular}{|c|c|}
\hline$V^{\mathrm{KR}}$ & Volume of TRISO kernel (fuel volume) \\
\hline$V_{i}^{\mathrm{TRISO}}$ & $\begin{array}{l}\text { Volumes of TRISO materials around } \\
\text { kernel }\end{array}$ \\
\hline$V^{\mathrm{com}}$ & Volume of fuel compact \\
\hline$V^{\text {TRISO }}$ & Volume of TRISO particle \\
\hline$V^{\text {TRISOinCOM }}$ & $\begin{array}{l}\text { Volume of TRISO particles in the } \\
\text { compact }\end{array}$ \\
\hline & $\begin{array}{l}\text { Volume fraction of TRISO materials } \\
\text { in the compact }\end{array}$ \\
\hline
\end{tabular}

Lengths $(\mathrm{cm})$

$r_{\mathrm{KR}} \quad$ Kernel radius (fuel radius)

$r_{i} \quad$ Kernel radius $r_{\mathrm{KR}}$ increased by material layer thickness $t_{i}$

$t_{i} \quad$ Material layer thickness

$r_{\text {сом }} \quad$ Radius of fuel compact

$h_{\text {сом }} \quad$ Height of fuel compact

$r_{\text {TRISO }} \quad$ Radius of TRISO particle

\section{Densities $\left(\mathrm{g} / \mathrm{cm}^{3}\right)$}

$\rho^{\mathrm{HOMO}}$

$\rho_{i}^{\mathrm{COM}}$

$\rho^{(\mathrm{HM}) \mathrm{O}_{2}}$

$\rho_{i}{ }^{(\mathrm{HM}) \mathrm{O}_{2}}$

Density of homogenized compact material

Densities of compact materials

Density of mixed dioxides

Density of each dioxide

\section{Masses (g)}

$m_{i}^{\mathrm{COM}}$

$m^{\text {СOM }}$

Mass of each material in the compact

Mass of the compact

\section{Weight fractions (-)}

$w_{i}{ }^{\mathrm{COM}, \mathrm{FR}}$ Weight fraction of each material in the compact

$w_{i}^{(\mathrm{HM}) \mathrm{O} 2, \mathrm{FR}}$ Weight fractions of each dioxide in the dioxide mix

$w_{i}^{\mathrm{U}} \quad$ Weight fractions of uranium isotopes in uranium

$w_{i}^{\text {IsO }} \quad$ Weight fractions of isotopes in no-fuel compact materials

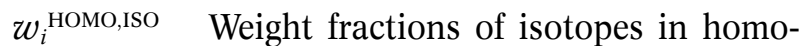
genized material mix for non-fuel materials

$w_{i}^{\mathrm{HOMO}(\mathrm{HM}) \mathrm{O}_{2}}$ Weight fractions of isotopes in homogenized material mix for fuel

$w_{i}^{(\mathrm{HM}) \mathrm{O}_{2}} \quad$ Weight fractions of each isotope in heavy metal dioxide

\section{Atom fractions (-)}

$a_{i}^{\mathrm{U}}$

Atom fractions of uranium isotopes in

$a_{i}^{(\mathrm{HM}) \mathrm{O}_{2}}$ uranium

metal dioxide

$a_{i}{ }^{(\mathrm{HM}) \mathrm{O}_{2}, \mathrm{FR}} \quad$ Atom fractions of each dioxide in the

Atom fractions of isotopes in no-fuel compact materials

\section{Atomic weights $(\mathrm{g} / \mathrm{mol})$}

$\mathrm{M}_{i}^{\mathrm{U}} \quad$ Atomic weights of each uranium isotope

$\overline{\mathrm{M}}^{\mathrm{U}} \quad$ Average atomic weight of uranium for

$\overline{\mathrm{M}}^{(\mathrm{HM}), \mathrm{MIX}}$ given enrichment

$\mathrm{M}_{i}^{(\mathrm{HM}) \mathrm{O}_{2}}$ Average atomic weight of the dioxide mix

$\mathrm{M}^{\mathrm{HM}}$

$\mathrm{M}^{\mathrm{O}}$

Atomic weights of each dioxide

atomic weight of oxygen

$\mathrm{M}_{i} \quad$ Atomic weights of other no-fuel isotopes of compact materials

$\bar{M} \quad$ Average atomic weight of other no-fuel elements in compact materials

$\overline{\mathbf{M}}^{(\mathrm{HM}) \mathrm{O}_{2}} \quad$ Average atomic weights of each dioxide

\section{Others}

$N^{\text {TRISO }}$

$N_{i}^{(\mathrm{HM}) \mathrm{O}_{2}}$

Number of TRISO particles in the fuel compact (-)

isotope in uranium dioxide (-)

$N^{(\mathrm{HM}) \mathrm{O}_{2}} \quad$ Number of atoms in the dioxide molecule (-)

$P \quad$ Packing fraction (\%)

TRISO TRi-structural ISOtropic. 